Disponível em:

http://editora.unoesc.edu.br/index.php/race

Race, Joaçaba, v. 14, n. 3, p. 957-982, set./dez. 2015

\title{
A ELETROBRAS É UMA BOA GESTORA DE FUNDOS SETORIAIS? UM ESTUDO SOBRE A RESERVA GLOBAL DE REVERSÃO
}

\section{Is Eletrobras a good sector funds manager? A study about the Global Reserve of Reversal}

\section{Rudolph Fabiano Alves Pedroza Teixeira}

E-mail: rudolphgp@hotmail.com Mestre em Economia pela Universidade Estadual Paulista Júlio de Mesquita Filho;

Graduado em Ciências Econômicas pela Universidade Federal de Juiz de Fora. Endereço para contato: Avenida Presidente Vargas, 409, Centro, 20071-003, Rio de Janeiro, Rio de Janeiro, Brasil.

Artigo recebido em 02 de dezembro de 2014. Aceito em 14 de julho de 2015. 
Resumo

A Eletrobras foi incumbida de financiar o setor elétrico brasileiro por meio dos recursos da Reserva Global de Reversão (RGR). Entretanto, com o advento da Medida Provisória n. 579, de 11 de setembro de 2012, depois convertida na Lei n. 12.783, de 11 de janeiro de 2013, o recolhimento da RGR deixou de ser compulsório. Somado a isso, o Projeto de Lei n. 355, de 2011, considerava que a Eletrobras concentrava as aplicações da RGR nas empresas por ela controladas, em detrimento das demais. A fim de investigar se a Eletrobras é uma boa gestora de recursos públicos e merece uma nova fonte de financiamento para o setor elétrico, verificou-se por intermédio de modelos econométricos que tanto as empresas do grupo Eletrobras quanto as demais grandes empresas são relevantes para explicar as liberações da RGR. Além disso, constatou-se que a Eletrobras, ao liberar recursos da RGR, não fez distinção entre grandes empresas ou pequenas cooperativas de eletrificação rural. Palavras-chave: Eletrobras. Financiamento. Setor elétrico brasileiro. RGR.

\section{Is Eletrobras a good sector funds manager? A study about the Global Reserve of Reversal}

\section{Abstract}

Eletrobras was mandated to finance Brazilian electricity sector through funds from the Reversion Global Reserve (RGR). However, with the advent of Provisional Measure No. 579 from September ${ }^{\text {th }}$, 2012, later converted into Law No. 12.783, from November $1^{\text {st }}$, 2013, the payment of RGR is no longer compulsory. Added to this, Bill No. 355, 2011, considered if Eletrobras focused applications of RGR in companies controlled by it, rather than the others. In order to investigate if Eletrobras is a good public resources manager and deserves a new source of funding for the electricity sector, it was found by the econometric models that both the Eletrobras group and the others big companies are relevant to explain the $R G R$ releases. Furthermore, it was found that Eletrobras, by releasing $R G R$, did not distinguish between large companies or small cooperatives of rural electrification.

Keywords: Eletrobras. Financing. Brazilian electricity sector. RGR.

\section{INTRODUÇÃO}

O objetivo fundamental das Centrais Elétricas Brasileiras (Eletrobras) é realizar estudos, projetos, construção e operação de usinas produtoras, linhas de transmissão e distribuição de energia elétrica que permitam o crescimento dos centros urbanos e dos polos industriais, além de contribuir com o desenvolvimento das regiões mais remotas do Brasil (A ENERGIA, 1977; LANDI, 2006).

Uma função atribuída à Eletrobras e pouco conhecida do público em geral diz respeito ao financiamento do setor elétrico brasileiro. Resumidamente, a Eletrobras recebe recursos (oriundos de tributos na conta de luz) do Governo 
Federal brasileiro e os repassa para as diversas concessionárias e permissionárias que atuam no setor elétrico nacional (PINTO JUNIOR, 1998; SILVA, 2011).

Entre os fundos setoriais administrados pela Eletrobras se destacam a Conta de Desenvolvimento Energético (CDE), a Conta de Consumo de Combustível (CCC) e a Reserva Global de Reversão (RGR). A primeira possui como funções a promoção de projetos de universalização dos serviços de energia elétrica, a promoção do programa de subvenção aos consumidores de baixa renda e a expansão da malha de gás natural para o atendimento dos estados que ainda não possuem rede canalizada; a segunda é utilizada para o pagamento do combustível utilizado pelas termoelétricas em operação nos sistemas isolados do país; e a última, atua no financiamento de diversos projetos do setor elétrico brasileiro (ECCARD, 2012; ELETROBRAS, 2015).

O relevante papel na gerência de recursos fiscais para o setor elétrico, principalmente a RGR, possibilitou o fortalecimento financeiro e a grande autonomia da Eletrobras holding, já que essa empresa assumiu o comando financeiro do setor elétrico nacional, propiciando a segurança necessária aos diversos empreendimentos de geração, transmissão e distribuição de energia (CACHAPUZ, 2002; FARIA, 2003).

Recentemente, a Medida Provisória n. 579, de 11 de setembro de 2012, depois convertida na Lei n. 12.783, de 11 de janeiro de 2013, impôs um novo desafio a todo sistema elétrico brasileiro ao estabelecer que sua principal fonte de financiamento, a RGR, deixaria de ser cobrada compulsoriamente (na prática, a RGR foi extinta). Segundo Gonçalves Junior (2002), a RGR era responsável por empréstimos a taxas de juro subsidiadas, tendo como escopo o financiamento dos investimentos em infraestrutura das empresas de energia elétrica, que são de longa maturação e possuem a característica de necessitarem de grandes volumes de recursos.

Nesse aspecto, a RGR cumpria um papel estratégico para a manutenção e o desenvolvimento do setor elétrico brasileiro, pois a maioria das empresas desse segmento não conseguiria empréstimos bancários a taxas de juro razoáveis para realizar seus investimentos (PINTO JUNIOR, 2007). Nem mesmo o Banco Nacional de Desenvolvimento Socioeconômico (BNDES) poderia auxiliar a maior parcela das empresas do setor, considerando que a política de financiamento desse banco contempla, aproximadamente, pouco mais da metade do valor de um grande projeto/programa de energia elétrica, o que, ainda assim, não atende às necessidades dessas empresas. 
Como a RGR era a principal linha de crédito do setor elétrico brasileiro, já que cumpria a função de proteger o sistema contra a ausência de recursos para os grandes projetos, seria importante que uma nova linha de crédito fosse repassada à Eletrobras para que ela pudesse continuar realizando sua função econômica e social, garantindo que o sistema elétrico brasileiro não se torne obsoleto e frágil, propenso a uma nova crise de abastecimento, como a que ocorreu no início do século XXI. ${ }^{1}$

A Lei n. 5.655, de 20 de maio de 1971, considerava que a Eletrobras, como administradora da RGR, deveria destinar esses recursos para a concessão de financiamento às concessionárias e permissionárias de energia elétrica, mediante projetos específicos de investimentos (CACHAPUZ, 2002). Dessa forma, de 1994 a 2010, a Eletrobras direcionou mais de $\mathrm{R} \$ 11,8$ bilhões $^{2}$ para as empresas e cooperativas de energia elétrica em todo o Brasil pelo fundo RGR. Tais recursos foram fundamentais para o processo de desenvolvimento do setor elétrico, bem como para auxiliar na redução das disparidades regionais e ampliar o bem-estar social.

A RGR foi responsável pelo financiamento de: projetos de construção de termoelétricas, hidroelétricas, usinas nucleares, etc.; interligação do sistema elétrico brasileiro a regiões antes consideradas isoladas; e expansão, reforço e manutenção da rede das concessionárias que atuam no atendimento direto ao consumidor (ELETROBRAS, 2015).

Somado a isso, o Programa Luz para Todos (LpT), que é referência mundial na redução das disparidades regionais e na inclusão energética da população de baixa renda, possuía como linha de crédito os recursos da RGR para financiamento e os recursos da CDE para subvenção (MINISTÉRIO DE MINAS E ENERGIA, 2015; TEIXEIRA; BERTELLA, 2012).

Assim, o fim da cobrança compulsória da RGR reduziu a segurança e o potencial de crescimento do setor elétrico brasileiro e, como reflexo disso, o enfraquecimento do suprimento de energia elétrica gerou um efeito negativo na cadeia elétrica, o qual se espraiou por toda a economia brasileira.

Esse resultado pode ser confirmado pelas visões de Dadalto (2008) e Castro (2012), que lembram a influência do uso da energia elétrica em diversas dimensões 
da vida cotidiana, como educação, comunicações, saúde, conforto e produtividade. O Diagrama 1, a seguir, mostra os impactos da eletricidade no dia a dia.

Diagrama 1 - Efeitos positivos da eletricidade para o desenvolvimento socioeconômico e o bem-estar

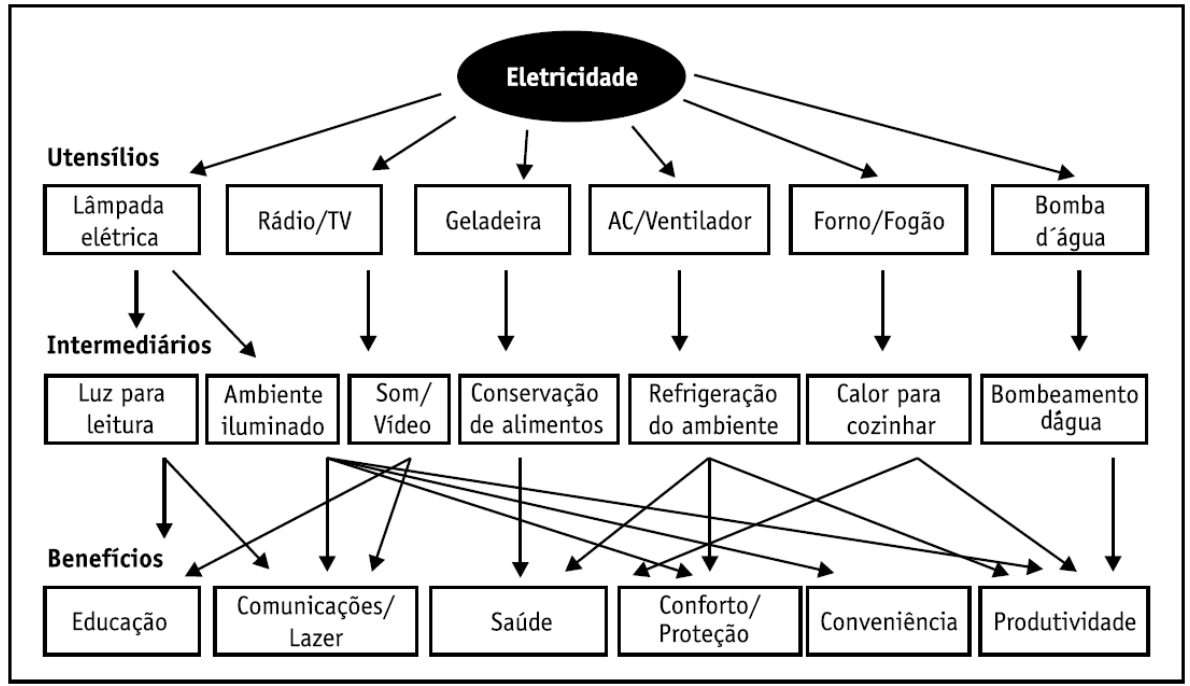

Fonte: adaptado de Lallement e Barnes (2005).

Dessa forma, pode-se concluir que o custo social e econômico pelo fim da RGR foi muito superior ao benefício pelo fim de sua cobrança na conta de luz. Para que se possa corrigir essa distorção, seria importante que a administração de uma nova fonte de recursos fosse repassada à Eletrobras, considerando-se as necessidades energéticas do Brasil.

Por sua vez, para que a Eletrobras possa pleitear uma nova fonte de financiamento para o setor elétrico brasileiro, existe um ponto muito importante que precisa ser analisado, o qual diz respeito ao período de atuação da Eletrobras como administradora da RGR. O Projeto de Lei n. 355, de 2011, considerava que a Eletrobras estava concentrando as aplicações da RGR nas empresas por ela controladas, em detrimento das demais. Ou seja, surgiu a hipótese de que a Eletrobras não administrou de maneira isonômica a RGR; nesse sentido, é preciso pesquisar se a gestão desta pela Eletrobras foi imparcial e cumpriu com o determinado em Lei.

Assim, o objetivo principal com este trabalho é investigar se a Eletrobras privilegiou suas empresas com os recursos da RGR em oposição às demais. Como objetivos secundários, pretendeu-se verificar se a Eletrobras cumpriu seu papel como agente estatal promotor do desenvolvimento econômico brasileiro ao aplicar 
o fundo RGR e contribuir com a literatura sobre o tema, ao se proporem modelos funcionais que possam explicar as liberações de recursos da RGR.

A sessão 2, a seguir, faz um levantamento da base de dados da RGR utilizada pela Divisão de Acompanhamento em Empreendimentos Financeiros (DFI), da Eletrobras durante o período de 1994 a 2010.

\section{ESTATÍSTICAS SOBRE A RGR}

Uma das contribuições mais importantes da RGR estava vinculada ao processo de desenvolvimento regional brasileiro. Por força da Lei n. 9.427, de 26 de dezembro de 1996 , em seu artigo $13^{\circ}$, parágrafo $2^{\circ}$, inciso II, no mínimo $50 \%$ dos recursos arrecadados pela RGR deveriam ser aplicados nas regiões Norte, Nordeste e Centro-Oeste.

Nesse aspecto, a Eletrobras, como gestora do fundo RGR, deveria buscar aplicar os recursos dessa fonte da forma mais eficiente possível, observando o disposto em Lei (LANDI, 2006). Uma maneira encontrada de verificar se a Eletrobras realizou uma boa gestão da RGR, no que se refere à Lei n. 9.427, é por meio da compilação de dados regionais referentes às liberações de recursos da RGR. A Tabela 1 expõe os resultados:

Tabela 1 - Liberações de recursos da RGR entre as regiões brasileiras (1994-2010)

\begin{tabular}{crr}
\hline Região & Liberado $(\mathbf{R} \$)$ & $\mathbf{\%}$ \\
\hline Centro-Oeste & $1.021 .646 .477,23$ & 8,62 \\
Nordeste & $2.935 .032 .669,04$ & 24,77 \\
Norte & $3.164 .206 .643,53$ & 26,71 \\
Sudeste & $2.886 .684 .291,55$ & 24,36 \\
Sul & $1.840 .419 .943,04$ & 15,53 \\
Total liberado & $11.847 .990 .024,39$ & 100 \\
\hline
\end{tabular}

Conforme pode ser observado na Tabela 1, durante o período de 1994 a 2010, aproximadamente, $60,1 \%$ dos recursos da RGR foram direcionados para as regiões Norte, Nordeste e Centro-Oeste. Ou seja, a análise empírica dos dados comprova que a Eletrobras cumpriu com o determinado pela Lei n. 9.427. Além disso, a região 
Norte é a que mais recebeu recursos da RGR no período, corroborando mais uma vez a boa gestão social e regional do fundo pela Eletrobras.

Nesse mesmo sentido, a Tabela 2, a seguir, mostra o número de empresas que atuam em algum ramo do setor elétrico (geração, transmissão ou distribuição), entre as distintas regiões brasileiras, e que receberam recursos da RGR:

Tabela 2 - Número de empresas do setor elétrico que receberam recursos da RGR (1994-2010)

\begin{tabular}{cr}
\hline Região & Empresas \\
\hline Centro-Oeste & 11 \\
Nordeste & 13 \\
Norte & 8 \\
Sudeste & 39 \\
Sul & 33 \\
Total de empresas & 104 \\
\hline Fonte: o autor. \\
Nota: ^Sem considerar os governos do Amazonas e Rondônia, que \\
não receberam recursos da RGR no período.
\end{tabular}

A Tabela 2 demonstra que, no total, 104 empresas do setor elétrico receberam recursos da RGR entre 1994 e 2010. Somando-se todas as empresas das regiões Centro-Oeste, Nordeste e Norte, obtém-se a quantia de 32 empresas, ao passo que as regiões Sudeste e Sul representam 72 empresas.

É importante destacar que as regiões Sudeste e Sul possuem um número maior de empresas ligadas ao setor elétrico, se comparadas às demais regiões. No entanto, o que se pode concluir da Tabela 2 é que, mesmo possuindo uma quantidade muito menor de empresas do setor elétrico que receberam recursos da RGR, as regiões Centro-Oeste, Nordeste e Norte, ainda assim, contaram com mais de 60\% desses recursos, ou seja, a Eletrobras soube canalizar os recursos da RGR para as empresas presentes nas regiões menos desenvolvidas do País, cumprindo sua função social como braço do Governo.

Outra forma de se verificar a distribuição das liberações dos recursos da RGR, durante o período de 1994 a 2010 é por meio dos programas contemplados por essa fonte. A Tabela 3 expõe a configuração encontrada: 
Tabela 3 - Liberações de recursos da RGR agrupadas por programa (1994-2010)

\begin{tabular}{lr}
\hline \multicolumn{1}{c}{ Programa } & Valor liberado (R\$) \\
\hline Conservação de energia & $234.764 .540,07$ \\
Controlador de demanda & $4.155 .888,46$ \\
Distribuição & $780.751 .529,21$ \\
Geração & $2.757 .555 .011,54$ \\
Luz no campo & $989.833 .003,71$ \\
Luz para Todos & $2.509 .633 .886,17$ \\
Pequenas centrais elétricas & $50.528 .716,19$ \\
Recuperação/revitalização de parques térmicos & $203.612 .391,34$ \\
Reluz & $326.447 .110,76$ \\
Sistema de supervisão, controle e automação & $11.540 .133,69$ \\
Sistema de telecomunicações & $19.414 .011,40$ \\
Transmissão & $2.446 .690 .341,51$ \\
Outros & $1.513 .063 .460,34$ \\
Total liberado & $11.847 .990 .024,39$ \\
\hline \hline
\end{tabular}

Fonte: o autor.

Conforme pode ser observado, as liberações de recursos da RGR contemplaram os mais variados tipos de programas ligados ao setor elétrico. Os investimentos realizados com essa fonte de recursos foram direcionados, principalmente, aos tradicionais programas de distribuição, geração e transmissão, além de dois grandes Programas de cunho social: o Luz no Campo (LnC) e o Luz para Todos (LpT).

Vale destacar que o Programa LnC foi lançado em dezembro de 1999 pelo então presidente Fernando Henrique Cardoso. Por sua vez, com a eleição de Lula para presidente, esse Programa foi substituído pelo LpT, o qual foi mantido pela atual presidente Dilma Roussef e possui duração estimada até o final de 2018 (PROGRAMA DE ACELERAÇÃO DO CRESCIMENTO, 2015).

Em relação aos programas de distribuição, geração e transmissão, estes receberam mais de 50\% dos recursos da RGR liberados entre 1994 e 2010, revelando a importância dos três principais segmentos que existem no setor elétrico. Por sua vez, os dois grandes programas sociais, LnC e LpT, mesmo entrando efetivamente em vigor a partir do ano 2000, representaram, aproximadamente, 29,5\% dos recursos liberados pela RGR. 
Em outras palavras, todas as análises anteriores fornecem fortes indícios de que a Eletrobras atendeu de maneira eficiente à demanda de recursos da RGR tanto para os principais programas de infraestrutura quanto para os principais programas sociais, demonstrando seu importante papel para as políticas públicas ligadas ao setor elétrico.

Por outro lado, o Projeto de Lei do Senado n. 355, de 2011, propunha retirar a administração do fundo RGR da Eletrobras, com a justificativa de que ela estaria concentrando as aplicações de recursos nas empresas por ela controladas, em detrimento das demais.

Assim, com este trabalho, procurou-se responder essa questão, que impacta diretamente na imagem da Eletrobras e na isonomia da gestão do fundo RGR. Inicialmente, elaborou-se um gráfico de barras com informações sobre as liberações de recursos da RGR durante o período de 1994 a 2010, o sub-período de 2002 a 2010 e o ano 2010, considerando dois grupos de empresas, um composto pelas empresas do Sistema Eletrobras e o outro composto pelas demais empresas do setor elétrico. ${ }^{3}$ Os resultados podem ser visualizados no Gráfico 1.

Gráfico 1 - Liberações de recursos da RGR

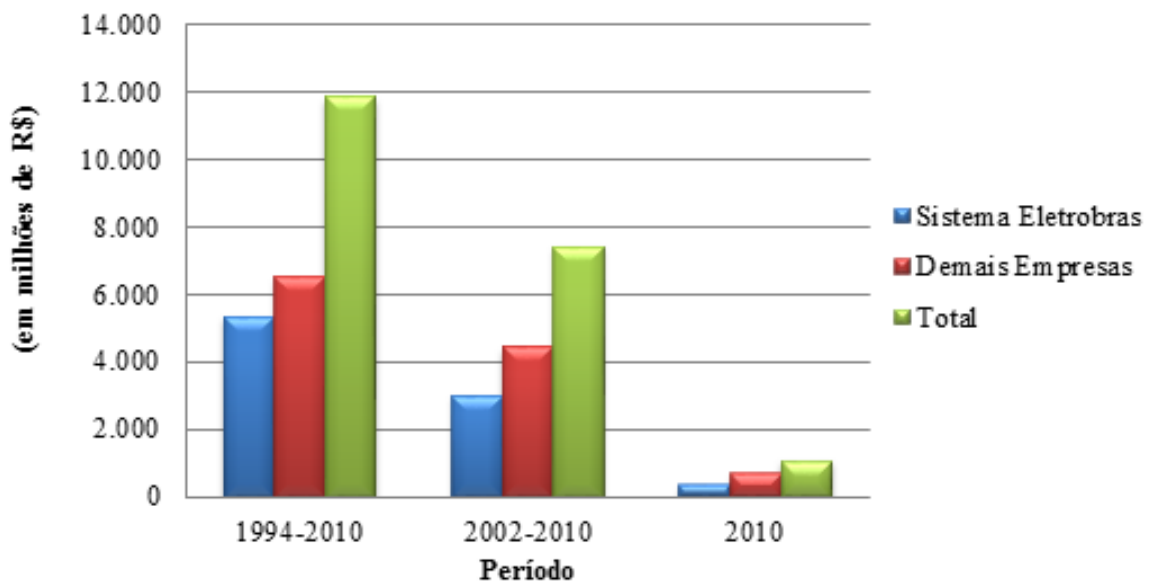

Fonte: o autor.

Considerando o período completo de análise (1994-2010), pode-se observar que 45,1\% dos recursos da RGR foram direcionados às empresas do Sistema Eletrobras, enquanto 54,9\% ficaram com as demais empresas. Por sua vez, no sub-período (2002-2010), a parcela de recursos da RGR liberada para as empresas 
do Sistema Eletrobras representou 40,4\%, ao passo que as demais empresas se beneficiaram com 59,6\%. Por fim, ao se investigar somente o ano 2010, verifica-se que $34,1 \%$ dos recursos da RGR foram destinados às empresas do Sistema Eletrobras e $65,9 \%$ às demais empresas.

Com os resultados encontrados, é possível identificar que durante os três períodos analisados, sempre as demais empresas obtiveram uma parcela maior de recursos da RGR se comparadas às empresas do Sistema Eletrobras. Além disso, uma clara tendência temporal foi encontrada no padrão de liberações de recursos da RGR. Com o passar dos anos, uma parcela cada vez maior dos recursos da RGR estaria sendo direcionada às demais empresas, em detrimento das empresas do Sistema Eletrobras. Isto é, o argumento utilizado no Projeto de Lei n. 355, de 2011, parece não se sustentar.

Para corroborar os resultados expressos pelo Gráfico 1, elaborou-se uma análise um pouco mais profunda, segregou-se o item "demais empresas" em duas partes: uma composta por 13 grandes empresas do setor elétrico e uma composta pelas "outras empresas" (demais grandes empresas, médias empresas, pequenas empresas e cooperativas de eletrificação rural). Como o Sistema Eletrobras possui 13 grandes empresas (Amazonas Energia, Boa Vista Energia, Ceal, Cepisa, Ceron, Chesf, CGTEE, Eletroacre, Eletronorte, Eletronuclear, Eletrosul, Furnas e Itaipu) que receberam recursos da RGR, a comparação com outras 13 grandes empresas privadas ou públicas do mesmo setor pode se mostrar esclarecedora. A Tabela 4 expõe os resultados:

Tabela 4 - Liberações de recursos da RGR para 13 grandes empresas do setor elétrico (em milhões R\$) (continua)

\begin{tabular}{lrrr}
\hline Empresa & $\mathbf{1 9 9 4 - 2 0 1 0}$ & $\mathbf{2 0 0 2 - 2 0 1 0}$ & $\mathbf{2 0 1 0}$ \\
\hline 1 - AES-Sul & 95,46 & 91,99 & 12,71 \\
2 - Celesc & 259,14 & 200,10 & 54,50 \\
3 - Celpa & 459,06 & 375,75 & 136,08 \\
4 - Celpe & 256,77 & 172,86 & 6,72 \\
5 - Celtins & 104,78 & 89,42 & 36,43 \\
6 - Cemar & 360,47 & 267,78 & 27,80 \\
7 - Cemat & 611,84 & 509,98 & 91,82 \\
8 - Cemig & 907,13 & 600,63 & 65,59 \\
9 - Coelba & 553,15 & 383,37 & 39,61 \\
10 - Copel & 527,29 & 166,25 & 38,12 \\
\hline
\end{tabular}




\begin{tabular}{lrrr}
\multicolumn{1}{c}{ Empresa } & $\mathbf{1 9 9 4 - 2 0 1 0}$ & $\mathbf{2 0 0 2 - 2 0 1 0}$ & (conclusão) \\
\hline 11 - Elektro & 136,61 & $\mathbf{2 0 1 0}$ \\
12 - Energisa-PB & 75,90 & 48,89 & 9,94 \\
13 - Escelsa & 156,26 & 147,02 & 3,66 \\
Total das 13 empresas & $4.503,86$ & $3.189,75$ & 2,70 \\
Sistema Eletrobras & $5.342,97$ & $2.990,74$ & 525,68 \\
Outras empresas & $2.001,15$ & $1.227,99$ & 165,86 \\
Total geral & $11.847,98$ & $7.408,48$ & $1.049,01$ \\
\hline Fonte: o autor. & & &
\end{tabular}

Durante o período de 1994 a 2010, as 13 grandes empresas estudadas receberam $38 \%$ dos recursos liberados da RGR, ao passo que as empresas do Sistema Eletrobras contaram com $45,1 \%$ desse montante. Isto se justifica até mesmo pelo tamanho do Sistema Eletrobras e pela maior parte de suas empresas estarem presentes nas regiões Centro-Oeste, Norte e Nordeste, onde as aplicações da RGR possuem percentual mínimo de $50 \%$ garantido por Lei. No mais, é importante lembrar que todas as demais empresas (total das 13 empresas somadas às "outras empresas") representaram $54,9 \%$ dos recursos da RGR, conforme destacado na análise anterior.

Considerando-se o período de 2002 a 2010, as 13 grandes empresas selecionadas receberam $43,1 \%$ das liberações de recursos da RGR, enquanto as empresas do Sistema Eletrobras contaram com 40,4\% da mesma fonte. Por sua vez, ao se investigar somente o ano 2010, é possível verificar que as 13 grandes empresas listadas foram representadas por $50,1 \%$ dos recursos liberados, enquanto que as empresas do Sistema Eletrobras corresponderam a 34,1\%.

De maneira geral, pode-se perceber que com o passar dos anos uma parcela cada vez maior de recursos da RGR foi direcionada às empresas de energia elétrica que não pertencem ao grupo Eletrobras. Adicionalmente, por ser o principal player do setor elétrico nacional e o maior sistema elétrico da América Latina, seria de se esperar que uma parcela significativa dos recursos da RGR fosse emprestada ao Sistema Eletrobras, o qual corresponde a 33\% da geração, $48 \%$ das linhas de transmissão e 31\% do território de distribuição do País, além de possuir seis empresas de geração e transmissão e seis empresas de distribuição (ELETROBRAS, 2014).

Nesse sentido, é possível inferir que a Eletrobras não tende a concentrar as aplicações do fundo RGR nas empresas por ela controladas em detrimento das demais. Na verdade, mesmo que a proposição levantada pelo Projeto de Lei n. 355 não pudesse ser rejeitada, ela parece não possuir fundamentação consistente. 
Destarte, a seção 3 pretende avaliar, por meio da teoria econômica e do ferramental da econometria, a hipótese proposta pelo Projeto de Lei n. 355, de 2011, de que a Eletrobras não geriu os recursos da RGR com isonomia e eficiência.

\section{AMOSTRA E ESPECIFICAÇÃO DOS MODELOS}

Este trabalho fez uso do software Gretl e de uma amostra em corte transversal (cross-section) de 54 empresas do setor elétrico, referentes ao ano 2010. A escolha desse ano justifica-se por apresentar os dados mais recentes e completos, até então, para todas as variáveis utilizadas no estudo. O Quadro 1 sintetiza a descrição das variáveis.

Quadro 1 - Descrição das variáveis utilizadas

\begin{tabular}{|c|c|c|c|}
\hline Variável & Descrição & $\begin{array}{l}\text { Sinal Es- } \\
\text { perado }\end{array}$ & Fonte \\
\hline$L I B_{i}$ & Logaritmo da Liberação de Recursos da RGR & & Eletrobras \\
\hline$R E C_{i}$ & Logaritmo da Receita & + & Aneel \\
\hline$C O N_{i}$ & Logaritmo do Número de Consumidores & + & Aneel \\
\hline$D 1_{i}$ & Variável Dummy. 1 se empresa, 0 se cooperativa. & $\star$ & O autor \\
\hline$E L T_{i}$ & $\begin{array}{l}\text { Variável Dummy. } 1 \text { se empresa do Sistema Eletrobras, } 0 \text { caso } \\
\text { contrário. }\end{array}$ & + & O autor \\
\hline$G R D_{i}$ & $\begin{array}{l}\text { Variável Dummy. } 1 \text { se grande empresa que não do Sistema } \\
\text { Eletrobras, } 0 \text { caso contrário. }\end{array}$ & + & O autor \\
\hline$N E O_{i}$ & $\begin{array}{l}\text { Variável Dummy. } 1 \text { se empresa do grupo Neoenergia, } 0 \text { caso } \\
\text { contrário. }\end{array}$ & + & O autor \\
\hline$E N E_{i}$ & $\begin{array}{l}\text { Variável Dummy. } 1 \text { se empresa do grupo Energisa, } 0 \text { caso con- } \\
\text { trário. }\end{array}$ & + & O autor \\
\hline$R E D_{i}$ & Variável Dummy. 1 se empresa do grupo Rede, 0 caso contrário. & + & O autor \\
\hline$F E C_{i}$ & Variável Dummy. 1 se cooperativa da Fecoergs, 0 caso contrário. & * & O autor \\
\hline
\end{tabular}

Fonte: o autor. 
A primeira equação proposta considera $L I B_{i}$ (logaritmo do montante liberado de recursos da RGR) a variável dependente e $E L T_{i}$ (variável dummy para distinguir as empresas do sistema Eletrobras das demais) e $G R D_{i}$ (variável dummy para separar as grandes empresas que não as do sistema Eletrobras das demais), as explanatórias. É importante informar que, quanto à última variável, o grupo de grandes empresas do setor elétrico foi aquele composto por empresas com mais de 350 mil consumidores em 2010. Assim, tem-se:

$$
L I B_{i}=\beta_{0}+\beta_{1} E L T_{i}+\beta_{2} G R D_{i}+\varepsilon_{i}
$$

na qual o termo de erro $\varepsilon_{i}$ possui média zero e variância constante. As letras gregas referem-se aos parâmetros a serem estimados.

Essa equação, aparentemente simples, possui dois objetivos bem definidos: observar se as empresas do grupo Eletrobras e as demais grandes empresas exercem influência significativa nas liberações de recursos da RGR e investigar se as empresas do grupo Eletrobras possuem maior impacto sobre as liberações de recursos da RGR se comparadas a outras grandes empresas do setor elétrico.

Assim, se $\beta_{1}$ for positivo (negativo) e estatisticamente significativo, pode-se concluir que as empresas do grupo Eletrobras influenciam positivamente (negativamente) nas liberações de recursos da RGR. Por sua vez, se $\beta_{2}$ apresentar sinal positivo (negativo) e mostrar-se significante do ponto de vista estatístico, conclui-se que as demais grandes empresas conseguem influir positivamente (negativamente) nas liberações de recursos da RGR.

Espera-se que $\beta_{1}$ e $\beta_{2}$ apresentem sinal positivo e sejam significantes, pois as empresas do Sistema Eletrobras e as outras grandes empresas do setor elétrico são as maiores demandantes de recursos da RGR em termos de volume. Além disso, se $\beta_{2}>\beta_{1}$, em magnitude, não é possível concluir que a Eletrobras beneficia suas empresas com os recursos da RGR em detrimento das demais.

A segunda equação proposta, por sua vez, possui uma forma funcional quase idêntica à da primeira. A novidade é a inclusão da dummy $D 1_{i}$, que procura 
distinguir as empresas do setor elétrico (públicas ou privadas) das cooperativas de eletrificação rural. A seguir está a fórmula da equação (2):

$$
L I B_{i}=\beta_{0}+\beta_{1} E L T_{i}+\beta_{2} G R D_{i}+\beta_{3} D 1_{i}+\varepsilon_{i}
$$

na qual o termo de erro $\varepsilon_{i}$ possui média zero e variância constante. As letras gregas referem-se aos parâmetros a serem estimados.

Os resultados esperados para os coeficientes $\beta_{1}$ e $\beta_{2}$ são os mesmos da equação (i). Em relação ao coeficiente $\beta_{3}$, dois resultados fariam sentido do ponto de vista econômico. Caso $\beta_{3}$ apresente sinal positivo e se mostre significante, pode-se concluir que as grandes empresas pressionam positivamente as liberações financeiras de recursos da RGR. O sinal positivo se justificaria tanto pela grande demanda de recursos financeiros quanto pelo maior número de projetos de investimentos dessas empresas se comparadas às cooperativas de eletrificação rural. Por outro lado, um coeficiente estatisticamente insignificante indicaria neutralidade nas liberações de recursos da RGR por parte da Eletrobras, já que esta não faria distinção entre grandes empresas e cooperativas do setor elétrico.

Por fim, a equação (3), a seguir, contempla as variáveis da equação (1), além de outras seis:

$$
\begin{aligned}
& L I B_{i}=\beta_{0}+\beta_{1} E L T_{i}+\beta_{2} G R D_{i}+\beta_{3} R E C_{i}+\beta_{4} C O N_{i}+\beta_{5} N E O_{i}+ \\
& \beta_{6} E N E_{i}+\beta_{7} R E D_{i}+\beta_{8} F E C_{i}+\varepsilon_{i}
\end{aligned}
$$

na qual o termo de erro $\varepsilon_{i}$ possui média zero e variância constante. As letras gregas referem-se aos parâmetros a serem estimados.

Nessa equação expandida, as variáveis $E L T_{i}$ e $G R D_{i}$ se juntam à $R E C_{i}$, que se refere ao logaritmo da receita do total das empresas e cooperativas à $C O N_{i}$, que diz respeito ao logaritmo do total dos consumidores das empresas e cooperativas à $N E O_{i}$, que é a variável dummy para empresas do grupo Neoenergia à variável dummy para empresas do grupo Energisa à $R E D_{i}$, variável dummy para empresas do 
grupo Rede; à $F E C_{i}$, variável dummy para as cooperativas pertencentes à Federação das Cooperativas de Energia, Telefonia e Desenvolvimento Rural do Rio Grande do Sul (Fecoergs).

Dessa maneira, espera-se que $\beta_{3}$ apresente sinal positivo e revele-se significativo, pois quanto maior a receita da empresa/cooperativa, maiores serão os valores concedidos para os projetos de investimentos que se enquadrem no âmbito da RGR, e, consequentemente, as liberações de recursos serão mais volumosas. A mesma interpretação pode ser feita para $\beta_{4}$.

Os coeficientes $\beta_{5}, \beta_{6}$ e $\beta_{7}$ dizem respeito à distinção entre empresas de três grandes grupos do setor elétrico. Assim, espera-se que todos apresentem sinal positivo e se mostrem significantes. Nesse aspecto, poderia-se concluir que os grupos Neoenergia, Energisa e Rede possuem influência determinística nas liberações de recursos da RGR.

Em relação ao coeficiente $\beta_{8}$, dois resultados seriam esperados. Caso ele apresente sinal positivo e revele-se significativo, entende-se que as cooperativas da Fecoergs têm impacto relevante sobre as liberações de recursos da RGR. Esse resultado seria aparentemente normal, considerando-se que essas cooperativas decidem conjuntamente sobre várias ações de investimento em programas de distribuição (atuam de forma coordenada). Por outro lado, um coeficiente insignificante do ponto de vista estatístico sugeriria que essas cooperativas não influenciam de forma relevante sobre as liberações do citado fundo.

\section{ANÁLISE DOS RESULTADOS}

Inicialmente, a equação (i) foi estimada por Mínimos Quadrados Ordinários (MQO), como forma de verificar a influência das empresas do grupo Eletrobras $E L T_{i}$ e das outras grandes empresas $G R D_{i}$ sobre as liberações financeiras dos recursos da RGR para programas/projetos do setor elétrico. O modelo 1 apresentado no Quadro 2, expõe os resultados: 
Quadro 2 - Modelo 1: Estimação da equação (i) por MQO

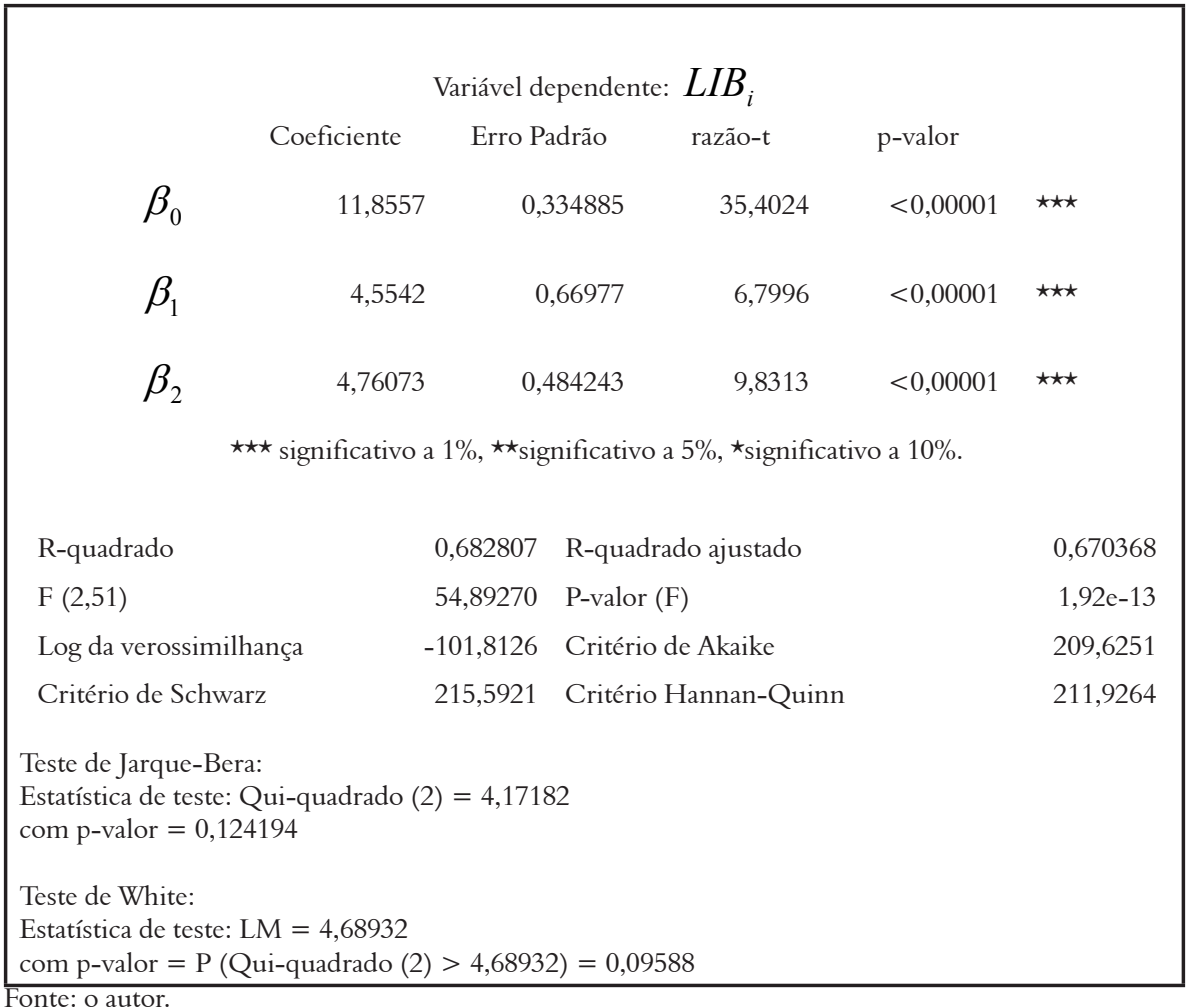

O modelo 1, apresentado no Quadro 2, reflete a estimação da equação (1) por MQO, e os resultados encontrados para os coeficientes foram os esperados, isto é, $\beta_{1}$ e $\beta_{2}$ apresentaram sinal positivo e mostraram-se significantes. Além disso, $\beta_{2}>\beta_{1}$, indicando que as demais grandes empresas possuem maior poder explicativo sobre as liberações de recursos da RGR se comparadas às empresas do grupo Eletrobras.

Em relação às estatísticas desse modelo, pode-se verificar que o conjunto de variáveis é significativo para explicar as liberações de recursos da RGR, já que a estatística $\mathrm{F}$ é igual a 54,89. Por sua vez, o ajuste dos dados à reta de regressão é bom, considerando-se que as variáveis independentes conseguem explicar, aproximadamente, $67 \%$ da variável dependente $\left(\mathrm{R}^{2}\right.$ ajustado $\left.=0,67\right)$. O teste JarqueBera indicou que os resíduos se distribuem, normalmente, a 10\% de significância, e o teste de White mostrou que não se pode rejeitar a hipótese de homocedasticidade a $5 \%$ de significância. 
A equação (2), por sua vez, considera todas as variáveis da equação (1), além da variável dummy $D 1_{i}$, que procura captar possíveis influências sobre as liberações de recursos da RGR, em decorrência da estrutura das firmas (se grandes empresas ou cooperativas). O modelo 2 no Quadro 3, a seguir, expõe os resultados:

Quadro 3 - Modelo 2: Estimação da equação (2) por MQO

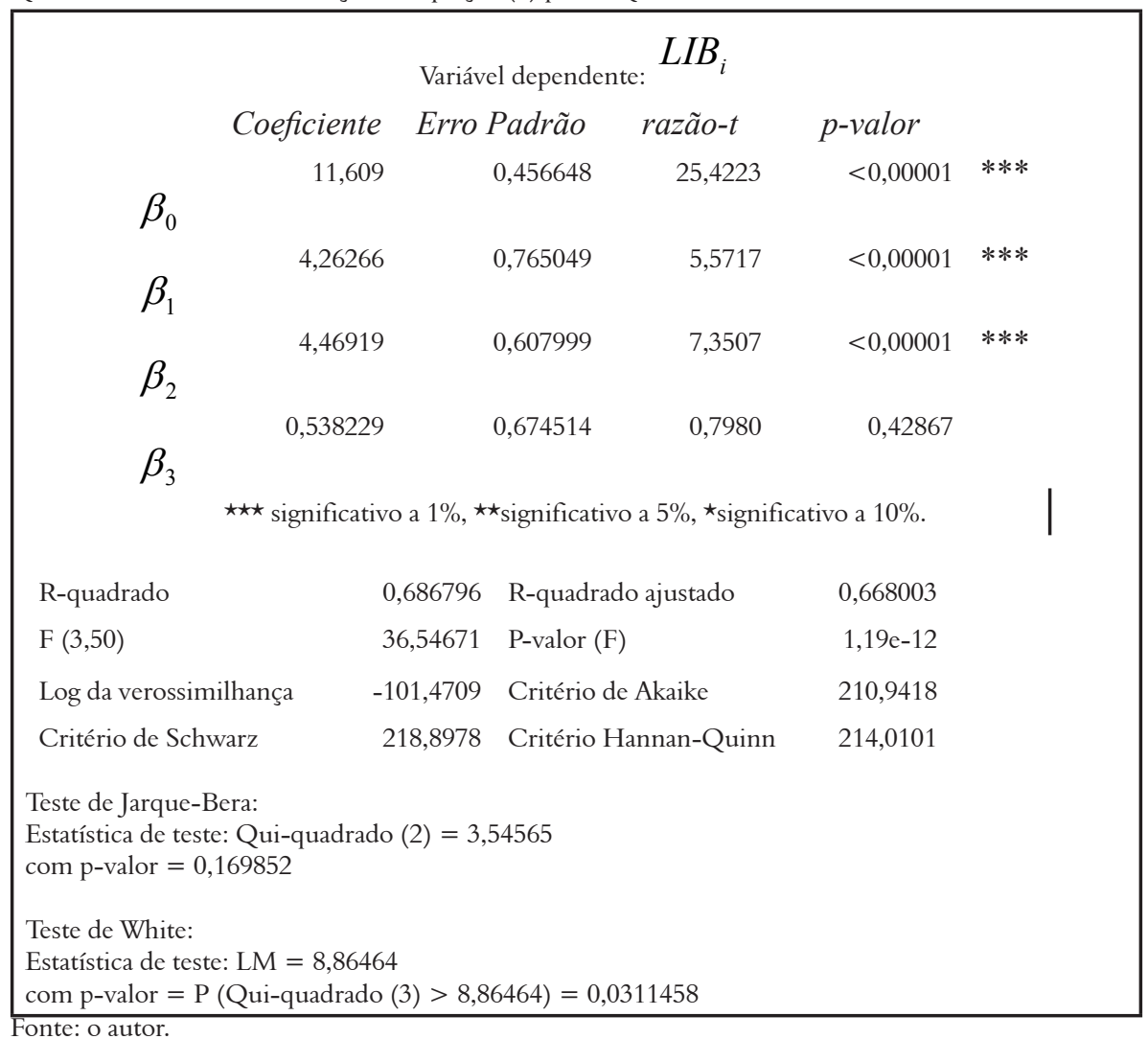

Fonte: $\mathrm{o}$ autor.

O modelo 2, apresentado no Quadro 3, mostrou os coeficientes $\beta_{1}$ e $\beta_{2}$ com sinais positivos e significativos do ponto de vista estatístico. Somado a isso, o coeficiente $\beta_{2}>\beta_{1}$, ratificando os resultados do modelo 1 , ou seja, tanto as empresas do grupo Eletrobras quanto as demais grandes empresas possuem influência sobre as liberações de recursos da RGR, no entanto, as últimas possuem maior relevância sobre a variável dependente. 
O coeficiente $\beta_{3}$, por sua vez, mostrou-se estatisticamente insignificante. Assim, não é possível afirmar que empresas públicas ou privadas influenciam positivamente nas liberações de recursos da RGR. Em outras palavras, pode-se considerar que não existe qualquer tendência por parte da Eletrobras em direcionar os recursos da RGR para as grandes empresas, em detrimento das cooperativas.

No mais, a estatística $F=36,55$ foi significativa, indicando que as variáveis em conjunto são relevantes para explicar as liberações de recursos da RGR, o R ${ }^{2}$ ajustado $=0,67$ apresentou um bom grau de ajuste da reta de regressão, o teste de Jarque-Bera sugeriu que os resíduos se distribuem, normalmente, a 10\% de significância e o teste de White foi significante a $1 \%$.

Por fim, estimou-se a equação (3), na busca de investigar duas importantes questões: verificar se a referida equação possui todas as variáveis relevantes para explicar as liberações de recursos da RGR e analisar se as liberações de recursos da RGR são influenciadas isoladamente por grandes grupos empresariais do setor elétrico. O resultado da regressão da equação (3) é explicitado pelo modelo 3, apresentado no Quadro 4, a seguir:

Quadro 4 - Modelo 3: Estimação da equação (3) por MQO

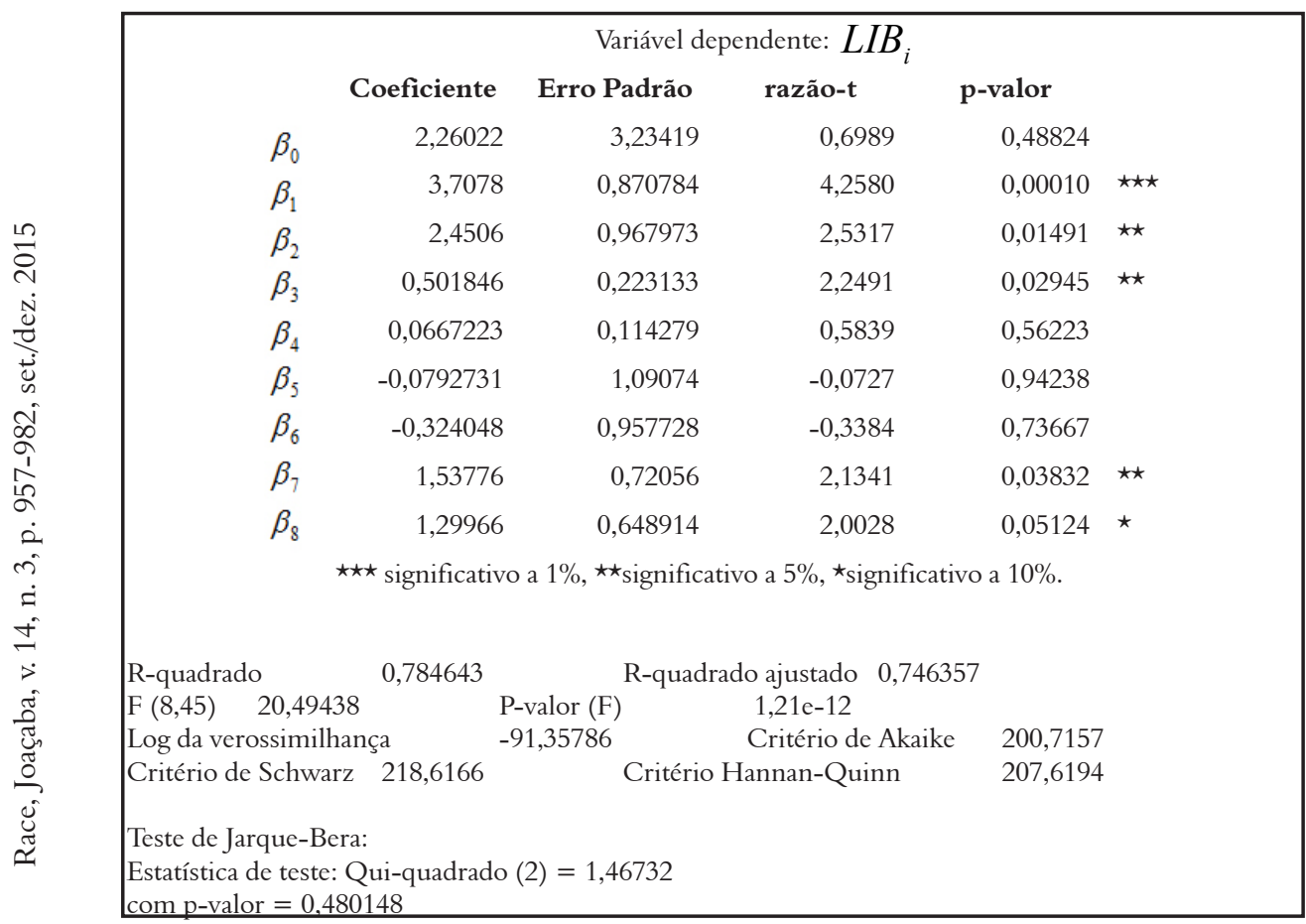

Fonte: $\mathrm{o}$ autor. 
Como nos modelos anteriores, os coeficientes $\beta_{1}$ e $\beta_{2}$ mostraram-se significativos, corroborando mais uma vez que tanto as empresas do grupo Eletrobras quanto as demais grandes empresas possuem poder explicativo sobre as liberações de recursos da RGR. Vale destacar que, ao contrário das demais estimativas, o coeficiente $\beta_{1}$ foi superior em magnitude ao coeficiente $\beta_{2}$.

O coeficiente $\beta_{3}$ também se revelou positivo e significante, conforme sugere a literatura. Quanto maior a receita da empresa, maior é a sua capacidade de obter financiamento, e, consequentemente, maiores serão as liberações de recursos da RGR. Já o coeficiente $\beta_{4}$ não confirmou as expectativas, mostrando-se irrelevante do ponto de vista estatístico. Em outras palavras, o número de consumidores das empresas de energia elétrica não é um fator que influenciou as liberações da RGR no período investigado.

Em relação aos coeficientes $\beta_{5}, \beta_{6}$ e $\beta_{7}$, somente o último revelou-se significativo e apresentou o sinal esperado. Ou seja, pode-se inferir que as empresas que fazem parte do grupo Rede influenciam positivamente sobre as liberações de recursos da RGR, porém, não é possível se afirmar o mesmo sobre as empresas do grupo Neoenergia e do grupo Energisa.

Por fim, o coeficiente $\beta_{8}$ apresentou sinal positivo e mostrou-se significante, indicando que as cooperativas da Fecoergs possuem influência positiva sobre as liberações de recursos da RGR. Isto é, a ação coordenada das cooperativas gaúchas é um fator importante para explicar o fluxo de liberações da RGR, demonstrando que a Eletrobras não faz distinções entre grandes empresas e pequenas cooperativas.

Além disso, o modelo 3 como um todo foi significativo, conforme o teste $\mathrm{F}$ $(\mathrm{F}=20,49)$, e a reta de regressão apresentou um ajuste muito bom ( $\mathrm{R}^{2}$ ajustado $=$ 0,75). O teste de Jarque-Bera indicou que os resíduos se distribuem, normalmente, a $10 \%$ de significância e o teste de White não permite negar a hipótese nula de homocedasticidade do modelo a $10 \%$ de significância.

Em suma, com os resultados dos três modelos, pode-se concluir que a Eletrobras não concentrou as aplicações da RGR nas empresas por ela controladas em detrimento das demais, conforme sugerido pelo Projeto de Lei n. 355, de 2011. Na verdade, a Eletrobras foi mais além, já que também não discriminou, em termos proporcionais, a destinação do fundo RGR entre as grandes empresas e as pequenas cooperativas de eletrificação rural. 
Além disso, é coerente que uma parcela significativa dos recursos da RGR fosse emprestada às próprias empresas do Sistema Eletrobras, considerando que estas correspondem a 33\% da geração, $48 \%$ das linhas de transmissão e $31 \%$ do território de distribuição no País, sendo considerado o principal player do setor elétrico nacional e o maior sistema elétrico da América Latina.

\section{CONSIDERAÇÕES FINAIS}

Uma função que era realizada pela Eletrobras, mas pouco conhecida pela sociedade, referia-se à gestão do extinto fundo da RGR. Basicamente, a Eletrobras utilizava os recursos desse fundo para financiar projetos/programas das diversas empresas de geração, transmissão e distribuição de energia elétrica espalhadas pelo país.

Como a demanda por energia tende a se expandir de forma consistente ao longo das próximas décadas, o sistema elétrico nacional não pode ficar desprovido de recursos para atender aos novos projetos. Assim, para que possíveis problemas atrelados ao lado da oferta sejam evitados, é importante que uma nova fonte de financiamento fique sob a guarda da Eletrobras.

Ocorreu que durante o período de atuação como administradora da RGR, o Projeto de Lei n. 355, de 2011, considerava que a Eletrobras estava concentrando as aplicações da RGR nas empresas do seu sistema, em detrimento das demais. $\mathrm{Ou}$ seja, surgiu a hipótese de que a Eletrobras não administrou de maneira isonômica a RGR. Nesse sentido, para que a Eletrobras possa pleitear a administração de uma nova fonte de financiamento para o setor elétrico, é importante verificar se a gestão da RGR foi imparcial e cumpriu com o que está determinado em Lei.

Para tanto, pôde-se verificar por meio de estatísticas construídas com dados sobre as liberações de recursos da RGR, durante o período de 1994 a 2010, os seguintes resultados:

a) $60,1 \%$ dos recursos liberados da RGR foram aplicados nas regiões Centro-Oeste, Nordeste e Norte, resultado que supera o percentual mínimo de 50\% disposto pela Lei n. 9.427, de 26 de dezembro de 1996;

b) mais de $50 \%$ dos recursos liberados da RGR foram empregados nos tradicionais programas de geração, transmissão e distribuição, ao passo que quase $30 \%$ dos mesmos recursos foram direcionados aos programas de cunho social LnC e LpT; 
c) no período investigado, 45,1\% das liberações da RGR foram direcionados às empresas do Sistema Eletrobras, enquanto 54,9\% recaíram sobre as demais empresas.

Por sua vez, a análise econométrica foi responsável por confirmar a validade de alguns modelos explicativos para as liberações de recursos da RGR, bem como para avaliar a hipótese de que a Eletrobras beneficiou suas empresas com os recursos da RGR, em detrimento das demais. Os principais resultados podem ser reportados da seguinte maneira:

a) na equação (1), os coeficientes $\beta_{1}$ e $\beta_{2}$ foram positivos e significativos, com $\beta_{2}>\beta_{1}$. Isto é, tanto as empresas da Eletrobras quanto as demais grandes empresas são significativas para explicar as liberações de recursos da RGR, mas as últimas possuem um poder explicativo maior;

b) na equação (2), os coeficientes $\beta_{1}$ e $\beta_{2}$ foram positivos e significativos, com $\beta_{2}>\beta_{1}$. Ou seja, os resultados encontrados na equação (1) foram confirmados. Por sua vez, o coeficiente $\beta_{3}$ não foi significativo, indicando que a Eletrobras não fez distinção entre grandes empresas (públicas, privadas ou pertencentes ao seu sistema) e cooperativas ao liberar recursos da RGR;

c) na equação (3), os coeficientes $\beta_{1}$ e $\beta_{2}$ mostraram-se positivos e significativos, mas desta vez, $\beta_{1}>\beta_{2}$, sugerindo que o poder explicativo das empresas da Eletrobras é maior que o das demais grandes empresas para as liberações de recursos da RGR. O coeficiente $\beta_{3}$ apresentou-se positivo e significante, confirmando a hipótese de que quanto maior a receita de determinada empresa, maior é a sua necessidade de recursos.

O coeficiente $\beta_{7}$ também foi positivo e significativo, indicando que empresas do grupo Rede influenciaram positivamente nas liberações de recursos da RGR. Por fim, o coeficiente $\beta_{8}$ foi positivo e significativo, 
sugerindo que as cooperativas da Fecoergs também possuem impacto relevante nas liberações de recursos da RGR.

Destarte, pode-se que concluir que a Eletrobras cumpriu seu papel social ao direcionar parcela significativa dos recursos da RGR para regiões carentes e programas de cunho social. Não se pode afirmar que a gestão da RGR beneficiou as empresas do Sistema Eletrobras, em detrimento das demais empresas, pois a maior parcela dos recursos dessa fonte foi recebida pelas últimas. Além disso, os modelos econométricos também não confirmaram a proposição do Projeto de Lei n. 355, de 2011, pois em todos os casos, tanto as empresas do grupo Eletrobras quanto as demais grandes empresas foram relevantes para explicar as liberações da RGR. Em outras palavras, a Eletrobras geriu o fundo RGR de modo eficiente, isonômico e dentro da Lei, o que dá respaldo para essa empresa administrar um novo fundo público voltado ao financiamento do setor elétrico brasileiro.

Notas explicativas:

${ }^{1}$ Goldenberg e Prado (2003) lembram que entre 01 de junho de 2001 e 01 de março de 2002, foi implementado um racionamento de energia que tinha como meta economizar $20 \%$ da energia elétrica do país. Tal fato obrigou o governo do então presidente Fernando Henrique Cardoso, a dar explicações à sociedade brasileira.

${ }^{2}$ Este montante não considera os recursos da RGR utilizados como subvenção, ou seja, repassados à Conta de Desenvolvimento Energético.

${ }^{3}$ As informações sobre as liberações de recursos da RGR foram obtidas por meio de software específico, utilizado pela Divisão de Acompanhamento em Empreendimentos Financeiros (DFIA) da Eletrobras. Vale destacar que a DFIA passa por auditorias constantes (interna, externa independente, Agência Nacional de Energia Elétrica (ANEEL), Controladoria Geral da União (CGU), etc.), o que garante a fidedignidade dos dados.

\section{REFERÊNCIAS}

A ENERGIA Elétrica no Brasil (da primeira lâmpada à Eletrobras). Rio de Janeiro: Biblioteca do Exército, 1977.

BRASIL. Lei n. 5.655, de 20 de maio de 1971. Dispõe sobre a remuneração legal do investimento dos concessionários de serviços públicos de energia elétrica, e dá outras providências. Diário Oficial da União, Brasília, DF, 21 maio 1971. Disponível em: < http://www.planalto.gov.br/ccivil_03/Leis/L5655.htm>. Acesso em: 08 jun. 2015. 
BRASIL. Lei n. 9.427, de 26 de dezembro de 1996. Institui a Agência Nacional de Energia Elétrica - ANEEL, disciplina o regime das concessões de serviços públicos de energia elétrica e dá outras providências. Diário Oficial da União, Brasília, DF, 27 dez. 1996. Disponível em: < http://www.planalto.gov.br/ccivil_03/LEIS/ L9427cons.htm >. Acesso em: 08 jun. 2015.

BRASIL. Lei n. 12.783, de 11 de janeiro de 2013. Dispõe sobre as concessões de geração, transmissão e distribuição de energia elétrica, sobre a redução dos encargos setoriais e sobre a modicidade tarifária; altera as Leis n. 10.438, de 26 de abril de 2002, 12.111, de 09 de dezembro de 2009, 9.648, de 27 de maio de 1998, 9.427, de 26 de dezembro de 1996, e 10.848, de 15 de março de 2004; revoga dispositivo da Lei n. 8.631, de 04 de março de 1993; e dá outras providências. Diário Oficial da União, Brasília, DF, 14 jan. 2013. Disponível em: <http:// www.planalto.gov.br/ccivil_03/_ato2011-2014/2013/lei/L12783.htm>. Acesso em: 08 jun. 2015.

BRASIL. Medida Provisória n. 579, de 11 de setembro de 2012. Dispõe sobre as concessões de geração, transmissão e distribuição de energia elétrica, sobre a redução dos encargos setoriais, sobre a modicidade tarifária, e dá outras providências. Diário Oficial da União, Brasília, DF, 12 set. 2012. Disponível em: < http://www.planalto.gov.br/ccivil_03/_ato2011-2014/2012/mpv/579.htm>. Acesso em: 08 jun. 2015.

\section{CACHAPUZ, P. B. B. O planejamento da expansão do setor de energia} elétrica: a atuação da Eletrobras e do Grupo Coordenador do Planejamento dos Sistemas Elétricos. Rio de Janeiro: Centro da Memória da Eletricidade, 2002.

CÂMARA DOS DEPUTADOS. Projeto de Lei n. 355, de 2011. Regulamenta a função de Examinador de Trânsito. Parecer do Relator Deputado Hugo Legal (PROS0RJ), pela rejeição, em 05 jun. 2014. Disponível em: < http://www.camara. gov.br/proposicoesWeb/fichadetramitacao?idProposicao $=491745>$. Acesso em: 06 jul. 2015.

CASTRO, L. B. A. Pobreza energética na América Latina: o papel do setor elétrico na promoção do desenvolvimento socioeconômico. In: ECCARD, F. P. et al. Monografias Premiadas Eletrobras 50 anos. Rio de Janeiro: Centro Internacional Celso Furtado de Políticas para o Desenvolvimento, 2012.

DADALTO, E. A. Utilização da energia solar para aquecimento de água pela população de baixa renda domiciliar em habitações populares. 2008. Monografia (Especialização em Construção Civil)-Universidade Federal de Minas Gerais, Belo Horizonte, 2008. 
ECCARD, F. P. A importância da Eletrobras para o desenvolvimento do setor elétrico brasileiro. In: ECCARD, F. P. et al. Monografias Premiadas Eletrobras 50 anos. Rio de Janeiro: Centro Internacional Celso Furtado de Políticas para o Desenvolvimento, 2012.

\section{ELETROBRAS. Relatório de Sustentabilidade 2014 das Empresas} Eletrobras. Rio de Janeiro, 2014.

ELETROBRAS. Reserva Global de Reversão. Rio de Janeiro. Disponível em: $<$ http://www.eletrobras.com/elb/data/Pages/LUMISFBD6DADEPTBRIE.htm>. Acesso em: 06 jun. 2015.

FARIA, V. C. S. O papel do project finance no financiamento de projetos de energia elétrica: caso da UHE Cana Brava. 2003. 180 p. Dissertação (Mestrado em Planejamento Energético)-Universidade Federal do Rio de Janeiro, Rio de Janeiro, 2003.

GOLDENBERG, J.; PRADO, L. T. S. Reforma e Crise no Setor Elétrico Brasileiro no Período FHC. Tempo Social, São Paulo, v. 15, n. 2, p. 219-235, 2003.

GONÇALVES JUNIOR, D. Reestruturação do setor elétrico brasileiro: estratégia de retomada da taxa de acumulação do capital? 2002. 260 p. Dissertação (Mestrado em Energia)-Universidade de São Paulo, São Paulo, 2002.

\section{LALLEMENT, D.; BARNES, D. The challenge of energy and poverty} reduction. Energy and Water - ESMAP. 2005.

LANDI, M. Energia elétrica e políticas públicas: a experiência do setor elétrico brasileiro no período 1934 a 2005. 2006. 219 p. Tese (Doutorado em Energia)-Universidade de São Paulo, São Paulo, 2006.

\section{MINISTÉRIO DE MINAS E ENERGIA. Programa Luz para Todos.}

Disponível em: < http://luzparatodos.mme.gov.br/luzparatodos/Asp/o_programa. asp >. Acesso em: 06 jul. 2015.

PROGRAMA DE ACELERAÇÃO DO INVESTIMENTO. Luz para todos é prorrogado até 2018 para atender a mais 228 mil famílias. Disponível em: <http://www.pac.gov.br/noticia/eb02f82f>. Acesso em: 06 jul. 2015.

PINTO JUNIOR, H. Q. Os novos mecanismos do financiamento: transformações recentes e desdobramentos para a indústria elétrica brasileira. In: OLIVEIRA, A.; PINTO JUNIOR, H. Q. (Org.). Financiamento do setor elétrico brasileiro: inovações financeiras e novo modo de organização industrial. Rio de Janeiro: Garamond, 1998. 
PINTO JUNIOR, H. Q. Economia da energia: fundamentos econômicos, evolução histórica e organização industrial. Rio de Janeiro: Elsevier, 2007.

SILVA, B. G. Evolução do setor elétrico brasileiro no contexto econômico nacional: uma análise histórica e econométrica de longo prazo. 2011. 162 p. Dissertação (Mestrado em Ciências)-Universidade de São Paulo, São Paulo, 2011.

TEIXEIRA, R. F. A. P; BERTELLA, M. A. A Importância do Programa "Luz para Todos" na Redução das Disparidades Regionais Brasileiras. In: ENCONTRO NACIONAL DA SOCIEDADE BRASILEIRA DE ECONOMIA POLÍTICA, 17., 2012, Rio de Janeiro. Anais... Rio de Janeiro, 2012.

\section{COMO CITAR ESTE ARTIGO:}

TEIXEIRA, Rudolph Fabiano Alves Pedroza. A Eletrobras é uma boa gestora de fundos setoriais? Um estudo sobre a reserva global de reversão. RACE, Revista de Administração, Contabilidade e Economia, Joaçaba: Ed. Unoesc, v. 14, n. 3, p. 957-982, set./dez. 2015. Disponível em: < http://editora.unoesc.edu.br/index.php/ race $>$. Acesso em: dia/mês/ano.

$\varangle$ Teixeira, R. F. A. P. (2015). A Eletrobras é uma boa gestora de fundos setoriais?

ঐे Um estudo sobre a reserva global de reversão. RACE, Revista de Administração, Contabilidade e Economia, 14 (3), p. 957-982. Recuperado em dia/mês/ano, de http:// editora.unoesc.edu.br/index.php/race 
